\title{
Biological and Molecular Characterization of Five Phomopsis Species Associated with Pear Shoot Canker in China
}

Qing Bai, Lifeng Zhai, Xiaoren Chen, Ni Hong, Wenxing Xu, and Guoping Wang, State Key Laboratory of Agricultural Microbiology; College of Plant Science and Technology, Huazhong Agricultural University; and National Indoor Conservation Center of Virus-free Germplasms of Fruit Crops, Wuham, Hubei 430070, China

\begin{abstract}
Bai, Q., Zhai, L. F., Chen, X. R., Hong, N., Xu, W. X., and Wang, G. P. 2015. Biological and molecular characterization of five Phomopsis species associated with pear shoot canker in China. Plant Dis. 99:1704-1712.

In recent years, a widespread canker disease that infects the branches of pear trees has been observed in many provinces in China; it kills the branches and results in high losses in fruit production. Symptomatic branches were collected for etiological isolation from 11 varieties of three pear species and from Malus pumila. Samples were collected from six provinces in China. In total, 143 Phomopsis isolates were obtained from 181 samples and these were identified as belonging to five species: Phomopsis fukushii ( $n=69$ isolates), Diaporthe eres $(n=31), P$. amygdali $(n=22)$, P. longicolla $(n=13)$, and D. neotheicola $(n=8)$. Pathogenicity tests showed that only the first three species induced lesions on nonwounded branches of Pyrus pyrifolia var. Cuiguan. All the fungal species induced branch cankers following wound inoculations, and tests with additional pear varieties showed significantly higher virulence levels for the first three species than the latter two. A host range evaluation suggested

that the five species could infect most fruit trees belonging to the Rosaceae family as well as some non-Rosaceous species. Virulence varied depending on the species of both host and pathogen. Isolates of Phomopsis amygdali had significantly higher virulence in all the tested Rosaceae plants. Correlations among the host, pathogen, and sampling regions were noted, and the morphology, growth rate, and sporulation of these species in varied media were also characterized. This study presents the first attempt to perform a broad survey and characterization of the Phomopsis spp. associated with the pear shoot cankers in China. This study shows that $D$. eres and $P$. amygdali are just as responsible for the pear shoot canker diseases as P. fukushii, and it expands the host and geographic ranges of the five species. This report provides useful information for understanding and improving management strategies for controlling this economically important disease.
\end{abstract}

In recent years, a canker disease that causes brown canker tissue around buds on the shoots, twigs, or large branches of pear trees has been widely observed in many provinces in China (e.g., Jiangxi, Jiangsu, Shandong, Hubei, Fujian, and Yunnan). Disease incidence can be as high as $20 \%$ in pear trees of the species Pyrus pyrifolia and $P$. communis and 5 to $10 \%$ in other pear species (Huang et al. 2014). This disease always kills the infected shoots or branches and the attached blossom and leaf buds, resulting in a blight of numerous branches and a large loss of fruit production. Furthermore, the disease also results in decay of the xylem tissues of the infected branches, allowing the branches to be easily broken by the wind, and it has even killed entire pear trees. It has become a serious problem that limits the growth of pear trees in many pear-cultivating areas in China.

Several fungal pathogens can reportedly infect pear shoots or branches, inducing canker, dieback, or the death of the infected organs; for example, fungi belonging to the genera Valsa (Sawamura et al. 1990), Phomopsis (Smit et al. 1996), and Botryosphaeria (Zhai et al. 2014). Furthermore, more than one species belonging to the same genus can induce the same disease. It has been difficult to make a definite diagnosis by depending only on the symptoms observed in the field or with a limited amount of samples. Until the present study, the identification of the canker pathogen was unconfirmed, although the disease was primarily known as the "pear shoot canker" induced by Phomopsis spp. because the observed symptoms were similar to

Corresponding authors: W. Xu; E-mail: xuwenxing@mail.hzau.edu.cn; and G. Wang; E-mail: gpwang@mail.hzau.edu.cn

*The $\boldsymbol{e}$-Xtra logo stands for "electronic extra" and indicates that three supplementary figures are published online.

Accepted for publication 8 May 2015.

http://dx.doi.org/10.1094/PDIS-03-15-0259-RE

(C) 2015 The American Phytopathological Society previous descriptions for $P$. pyrifolia in Japan (Nasu et al. 1987; Tanaka and Endo 1930).

China is an important pear-growing country and leads other countries in pear cultivation; therefore, the identification and prevention of this disease has economic significance. China is also a likely center of origin for the pear. It is one of two genetic diversity subcenters for this fruit (Rubtsov 1944; Vavilov 1951; Wu et al. 2013; Zeven and Zhukovsky 1975), and numerous varieties and many species are cultivated. Therefore, studying the pathogens and their diverse ways of infecting pear trees of different varieties and species in China should provide important information for understanding the pear shoot canker. A broad survey for and characterization of Phomopsis spp. that infect pear trees is still lacking in China. Whether the disease is induced by the Phomopsis fungus remains unknown and,, if so, it is unclear which species is responsible for the disease in different host varieties or species in different provinces. Given the significance of identifying the disease and characterizing the responsible pathogens, we collected numerous samples from most provinces where the disease occurs in China and isolated and identified the pathogens responsible for the disease. This study provides useful information for understanding this economically important disease.

\section{Materials and Methods}

Field symptom survey, sample collection, and pathogen isolation. Field symptom surveys were carried out in 17 orchards with random screening of 141 trees in a total in six provinces (Jiangxi, Jiangsu, Shandong, Hubei, Fujian, and Yunnan) in China from May 2013 to May 2014. Samples with canker symptoms were collected from the branches of $P$. pyrifolia (vars. Cuiyu, Cuiguan, Chuxialv, Huanghua, Minfu, and Qingxiang), P. bretschneideri (vars. Suli and Zaobaisu), P. communis (vars. Packham, J6, and J23), and Malus pumila (var. Fushi) in the surveyed orchards.

Infected tissues ( 4 to $5 \mathrm{~mm}^{2}$ ) were excised from the xylem or phloem under the canker lesions neighboring the asymptomatic regions after they were surface sterilized with $0.1 \% \mathrm{HgCl}_{2}$ for $1 \mathrm{~min}$ and $75 \%$ ethanol for $1 \mathrm{~min}$, then rinsed twice with sterilized 
water and air dried. The excised tissues were placed on potato dextrose agar (PDA; $20 \%$ diced potato, $2 \%$ glucose, and $1.5 \%$ agar) petri plates and incubated at $25^{\circ} \mathrm{C}$ in the dark for 3 to 5 days until fungal colony formation. Each isolate was further purified by culturing a single conidium. In brief, an isolate was cultured on PDA at $25^{\circ} \mathrm{C}$ with a photoperiod of $14 \mathrm{~h}$ to induce sporulation The conidia produced were rinsed with sterilized water and diluted to a low concentration. The conidial dilutions were spread on PDA to generate discrete colonies, and six colonies of each isolate were selected and stored in $25 \%$ glycerol at $-70^{\circ} \mathrm{C}$ for later use.

DNA extraction, amplification, sequencing, and phylogenetic analysis. Fungal genomic DNA was extracted according to a previous description (Freeman et al. 1996). In brief, mycelia were ground into a fine powder in liquid nitrogen, dissolved in cetyltrimethylammonium bromide (CTAB) buffer $(2.0 \%$ [wt/vol] CTAB, $1,420.0 \mathrm{mM} \mathrm{NaCl}$, $20.0 \mathrm{mM}$ EDTA, $100.0 \mathrm{mM}$ Tris $\mathrm{HCl}$ [pH 8.0], and $0.2 \%$ [wt/vol] $\beta$-mercaptoethanol), incubated at $65^{\circ} \mathrm{C}$ for $30 \mathrm{~min}$, combined with an equivalent volume of phenol/chloroform, and centrifuged at 12,000 rpm for $10 \mathrm{~min}$ to remove the precipitated segments. The genomic DNA was dissolved in Tris-EDTA buffer $(10.0 \mathrm{mM}$ Tris- $\mathrm{HCl}$ and $1.0 \mathrm{mM}$ EDTA, pH 8.0) after being precipitated by isopropanol. The extracted DNA was subjected to a polymerase chain reaction (PCR) amplification of three regions, including the ribosomal internal transcribed spacer (ITS; including a partial 18S ribosomal RNA [rRNA] gene, ITS1, 5.8S rRNA gene, ITS2, and partial 28S rRNA gene), translational elongation factor subunit $1-\alpha$ gene $(\mathrm{EF} 1 \alpha)$, and actin (ACT) by using the primer pairs ITS1/ITS4, ACT547F/ACT768R (Baumgartner et al. 2013), and EF1-728F/EF1-986R (Carbone and Kohn 1999). The PCR conditions for all the genomic regions were $2 \mathrm{~min}$ at $95^{\circ} \mathrm{C}$; followed by 35 cycles of $95^{\circ} \mathrm{C}$ for $60 \mathrm{~s}, 55^{\circ} \mathrm{C}$ for $60 \mathrm{~s}, 72^{\circ} \mathrm{C}$ for $90 \mathrm{~s}$; and then $10 \mathrm{~min}$ at $72^{\circ} \mathrm{C}$ in a PCR Thermal Cycler (Model PTC-100; MJ Research). The PCR products were then gel purified with an agarose gel DNA purification kit (Wuhan More Biotechnology Corporation) and commercially sequenced by Nanjing Jinsirui Biotechnology Co., Ltd.

The sequences were subjected to a homologous sequence search in the database of the National Center for Biotechnology Information by using the basic local alignment search tool (BLASTn) to provide an approximate identification of the isolates. Sequences for the available ex-type cultures were obtained from GenBank. Multiple sequence alignments were performed with DNAMAN (version 5.2.2; Lynnon Biosoft), and a phylogenetic tree was constructed by the neighbor-joining method using the 1,000 bootstrap replicates in MEGA 5.2 (Tamura et al. 2011).

Colony morphologies, conidial morphologies, and growth rate analysis. To characterize the morphology, a purified isolate was established from a 7-day-old mycelial plug (4 mm in diameter) placed in the center of $9-\mathrm{cm}$ petri dishes containing PDA. Cultures were incubated at $25^{\circ} \mathrm{C}$ with a photoperiod of $14 \mathrm{~h}$ until pycnidium formation. The colony appearance was recorded daily. The released conidia were diluted to a low concentration and observed under an optical microscope (Nikon Eclipse E600 FN; Nikon); 50 conidia were measured and then photographed with the SPOT program (version 4.6; Diagnostic Instruments, Inc.). These measurements were made in triplicate on three separate plates of each isolate.

Growth rate was quantified by similarly establishing each isolate on PDA. Cultures were incubated in triplicate at $25^{\circ} \mathrm{C}$ in the dark. The colony diameters were recorded daily until 7 days had passed, and their average diameters were statistically analyzed. The growth rate of each isolate was calculated by dividing the average colony diameter measured at 6 days after inoculation by 6 .

Sporulation properties and germination tests. Barleycorn and pome juice decoction media were prepared according to a previous report (Zhao et al. 2012), with some modifications. In brief, $70.0 \mathrm{~g}$ of barleycorn in its shell was soaked in water for $1 \mathrm{~h}$, moved to a conical flask, mixed with $20.0 \mathrm{ml}$ of $6.0 \%$ honey and $20.0 \mathrm{ml}$ of $1.0 \%$ peptone, and sterilized at $121^{\circ} \mathrm{C}$ for $40 \mathrm{~min}$; for the decoction, $300.0 \mathrm{~g}$ of mature pear fruit was mashed, the juice was squeezed through a multilayer gauze filter into a container, $300.0 \mathrm{ml}$ of distilled water and $30.0 \mathrm{~g}$ agar were added, and the mixture was sterilized at $121^{\circ} \mathrm{C}$ for $20 \mathrm{~min}$. Corn flour and Czapek medium were prepared according to another report (Fang 1998). In brief, $300.0 \mathrm{~g}$ of corn flour and $17.0 \mathrm{~g}$ of agar were diluted with distilled water into $1,000.0 \mathrm{ml}$ and then sterilized at $121^{\circ} \mathrm{C}$ for $20 \mathrm{~min}$; for the Czapek medium, $2.0 \mathrm{~g}$ of $\mathrm{NaNO}_{3}, 1.0 \mathrm{~g}$ of $\mathrm{K}_{2} \mathrm{HPO}_{4}, 0.5 \mathrm{~g}$ of $\mathrm{KCl}, 0.5 \mathrm{~g}$ of $\mathrm{MgSO}_{4} \cdot 7 \mathrm{H}_{2} \mathrm{O}, 0.01 \mathrm{~g}$ of $\mathrm{FeSO}_{4}$, and $30.0 \mathrm{~g}$ of sucrose were quantified, brought up to a $1,000.0-\mathrm{ml}$ volume with distilled water, and sterilized at $121^{\circ} \mathrm{C}$ for $20 \mathrm{~min}$.

A sporulation test was performed using colonized plugs to inoculate the centers of three petri dishes containing the medium described above. Plates were incubated at $25^{\circ} \mathrm{C}$ for a photoperiod of $14 \mathrm{~h}$ per day. Sporulation and conidium release were considered according to the formulation of pycnidia and the appearance of spore tendrils on the medium, respectively.

Conidial germination was evaluated by dropping $20.0 \mu \mathrm{l}$ of spore suspension diluted in potato-glucose (PD) solution $(20.0 \%$ diced potato and $2.0 \%$ glucose) on a glass slide, which was moved to a petri dish over several water-soaked filter papers to maintain high humidity, cultured at $25^{\circ} \mathrm{C}$ in the dark, and observed each hour postincubation under an optical microscope (Nikon Eclipse E600 FN; Nikon). Five microscope views with $\times 200$ magnification, containing approximately 70 to 80 conidia in the each, were randomly observed for each slide until all the conidia observed germinated.

Pathogenicity analysis, host range analysis, and virulence assessment. A spore suspension was prepared by inoculating plates of barleycorn medium with mycelial plugs as described above, growing the cultures for 8 days at $25^{\circ} \mathrm{C}$ with a 14-h photoperiod, then rinsing the plates with PD solution to release spores and further diluting the spore suspension with PD solution to a final concentration of $10^{6}$ conidia/ml.

Intact branch inoculations were performed on 1-year-old branches of 3-year-old potted pear trees ( $P$. pyrifolia var. Cuiguan) that were cultivated outdoors in Wuhan, Hubei province, China, from midMarch to April 2013 during the inoculation tests. Trees almost terminated their dormant period at the time of inoculation. The average daily lowest temperature was $13^{\circ} \mathrm{C}$ and the highest temperature was $21^{\circ} \mathrm{C}$, with an average monthly rainfall of $137.0 \mathrm{~mm}$ after inoculation. Given an unwounded tree, a 20.0- $\mu$ l aliquot of spore suspension $\left(10^{6}\right.$ conidia/ml) was coated (using a pipette) onto a bud and its neighboring regions after they were disinfested by swabbing the branches with cotton balls containing $75 \%$ ethanol. PD solutions containing no conidia were used in parallel as controls. For wounded trees, intact branches that were 7.0 to $11.0 \mathrm{~mm}$ in diameter were disinfested with $75 \%$ ethanol, and a hole was punched between two of the closer buds with a puncher ( $5 \mathrm{~mm}$ in diameter) on each shoot. A colonized PDA plug ( $5 \mathrm{~mm}$ in diameter) was excised from the colony margins after being cultured on PDA at $25^{\circ} \mathrm{C}$ for 3 days, inoculated in the hole of each shoot, and wrapped with plastic film strips to maintain high humidity until 10 days postinoculation (dpi). Noncolonized PDA plugs were used in parallel as controls. The symptoms were monitored and recorded every 10 days until the experiment was complete. Each bud from one branch of an individual tree was used for each inoculation treatment, and two independent experiments were performed.

Inoculation of detached mature pear fruit ( $P$. bretschneideri var. Huangguan) was performed by placing mycelium plugs on the skin over wounds (approximately $1.0 \mathrm{~mm}$ in depth) that had been prepared by puncturing the fruit three times with a needle. The mycelia plugs were covered with sterilized moist cotton balls and the inoculated fruit were incubated at $25^{\circ} \mathrm{C}$ in plastic containers covered with a plastic film. Three fruit were used for each inoculation treatment, and the symptoms were recorded daily.

Inoculation of detached branches was performed using 1-year-old branches ( $10.0 \mathrm{~cm}$ in length, 6.5 to $10.0 \mathrm{~mm}$ in diameter) with mycelia plugs in punched holes that were then covered with sterilized moist cotton balls and incubated under the same conditions as described above. Six branches were used for each inoculation treatment and the symptoms were recorded at $10 \mathrm{dpi}$.

Statistical analysis. Data were analyzed with SPSS Statistics 21.0 (WinWrap Basic; http://www.winwrap.com) by one-way analysis of variance, and means were compared using Tukey's test at 
a significance level of $P=0.05$. Homogeneity of variance was tested before analysis.

\section{Results}

Field symptom survey. The typical symptoms of the disease were always observed around the buds on shoots, twigs, or large branches, starting with small, sunken lesions that gradually expanded into oval or long cankers in March. The lesions were dark or reddish brown in appearance, with warped epidermal layers in some locations (Fig. 1A). As the lesions spread into the surrounding shoots or branches or merged together, the infected shoots or branches together with the attached leaves and buds were killed, and dieback in the areas above the lesions became visible by April to June (Fig. 1B). Under droughty circumstances or seasons, the lesions turned into darkbrown, stiff, shrunken depressions after dehydration, with cracks separating the diseased from the healthy tissues and the epidermal layers sloughing off the dried bark, leaving lesions with a reddish brown color and a withered, dried-up appearance (Fig. 1C). In one serious situation, most of the branches and even an entire pear tree were killed (Fig. 1D). In late summer, numerous small black protuberant spots (pycnidia) formed along the lenticels on the diseased bark (Fig. 1E), and the pycnidia released slim, round, curly white spore tendrils after rainfall in late summer (Fig. 1.F).

Isolation and molecular phylogenetic analysis. Using symptomatic samples collected from six provinces in China, we recovered 181 fungal isolates from three pear species (11 varieties) and from apple trees. Of these, 143 isolates exhibited the colony morphologies of Phomopsis spp. The other 38 isolates were identified as species of Pestalotiopsis (8 isolates), Botryosphaeria (9 isolates), Alternaria (6 isolates), and Valsa (13 isolates) based on their morphology and ITS sequences (data not shown), and those isolates were not included in further studies. All the Phomopsis isolates initially appeared as small, sparse white colonies but colony morphology diverged after 7 days of incubation on PDA medium plates at $25^{\circ} \mathrm{C}$ in the dark.
For species identification, 100 isolates that included the full range of colony morphologies were subjected to PCR amplification of their ITS sequences. The target DNA bands (approximately 507 to $547 \mathrm{bp}$ in length) were sequenced and aligned, indicating similarities ranging from 74.08 to $100 \%$. BLASTn searches of the ITS sequences showed that these colonies shared considerably high similarities (more than $75.0 \%, \mathrm{E}=4 \mathrm{e}^{-54}$ ) with Phomopsis spp., including Phomopsis fukushii, Diaporthe eres (anamorph P. oblonga (Desm.) Traverso), $P$. amygdali, $P$. longicolla, and D. neotheicola (anamorph: P. theicola Curzi). Phylogenetic analysis based on the ITS sequences with those of the Phomopsis spp. revealed that the 100 isolates clustered together with five fungal species (Fig. 2). In all, 22 representative isolates belonging to the five species $(9,4,3,3$, and 2 isolates, respectively) were further selected from the 100 isolates according to their colony morphologies, and their actin and EF1- $\alpha$ gene regions were sequenced. The 22 isolates were further subjected to phylogenetic analysis based on the concatenated sequences, including EF1- $\alpha$, actin, and ITS. Similar clades statuses were obtained for the respective isolates of the five species compared with the phylogenetic analysis based on the ITS sequences (Supplementary Fig. S1), confirming the species identification.

Relationships among Phomopsis spp., hosts, and sampling regions. $P$. fukushii isolates were frequently isolated from Pyrus communis and M. pumila (both of which were collected from Shandong); less frequently from $P$. pyrifolia collected from Jiangxi, Hubei, Fujian, and Jiangsu; and not at all from $P$. bretschneideri collected in Yunan province (Table 1). D. eres was isolated from all host species collected from all the provinces except Jiangsu, where only two samples were collected. It was one of only two species recovered from P. bretschneideri collected in Yunan province (Table 1). Phomopsis amygdali and $P$. longicolla were only isolated from Pyrus pyrifolia collected from Jiangxi and Fujian, except Phomopsis longicolla was also collected from the additional province of Hubei (Table 1). D. neotheicola

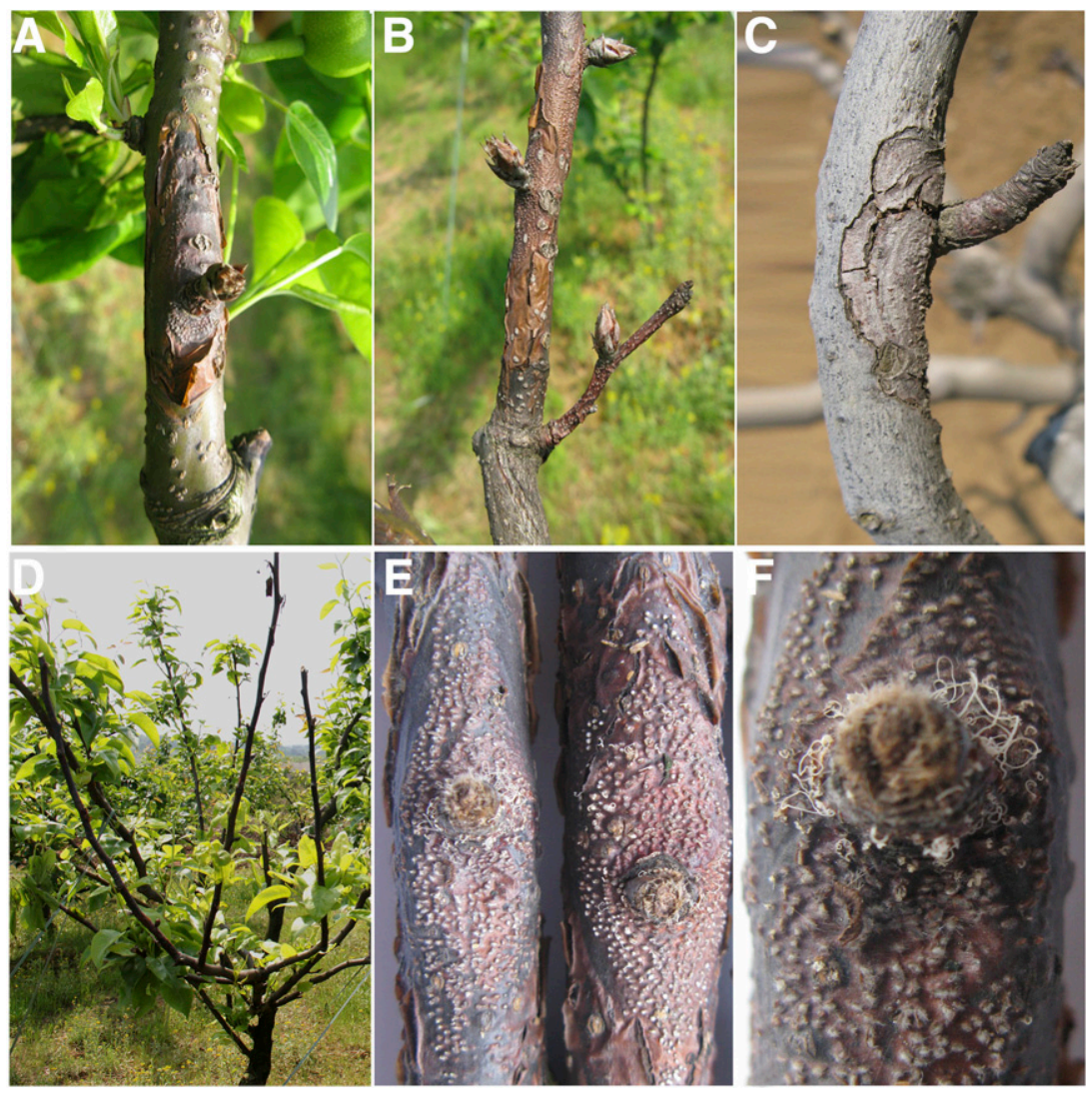

Fig. 1. Typical canker symptoms on branches of Pyrus pyrifolia var. Cuiguan in the field. A, Newly developed reddish-brown canker lesion around a bud; B, dieback symptoms resulting from lesion expansion around the branches; $\mathbf{C}$, withered symptom of an infected branch; $\mathbf{D}$, severe branch dieback or wilt of an infected tree; $\mathbf{E}$, pycnidia formed on the lesions; $\mathbf{F}$, white spore tendrils released from pycnidia. 
was isolated most frequently from Pyrus bretschneideri that was collected in Yunan province (five of eight isolates), occasionally from $P$. pyrifolia from Jiangxi and Fujian, but not from other host species or provinces (Table 1).

Colony morphologies, conidial morphologies, and growth rate analysis. Characterization of the colony morphologies for the five Phomopsis spp. after 10 days of incubation on PDA

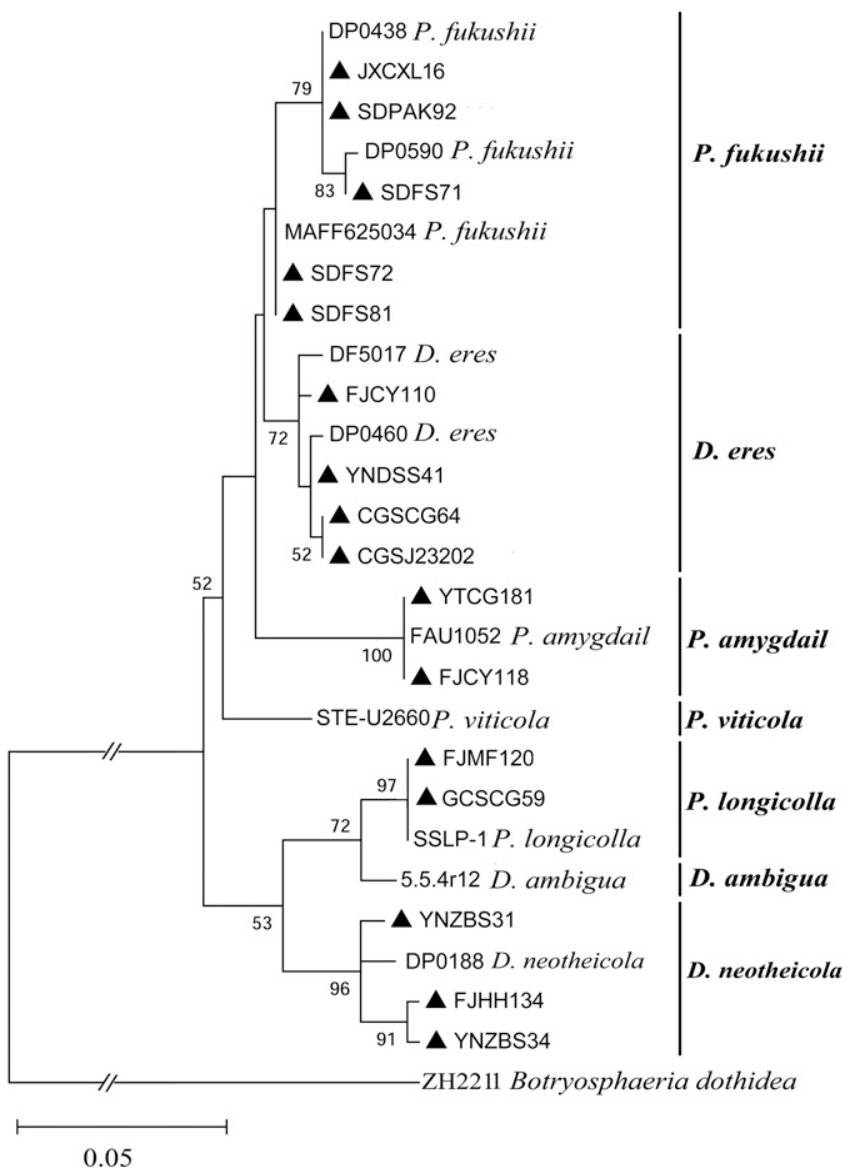

Fig. 2. Maximum-likelihood phylogenetic analysis of isolates obtained during this study along with Phomopsis (Diaporthe) spp. isolates registered in the GenBank database on the basis of their internal transcribed spacer (ITS) sequences. A heuristic search was performed with a bootstrap value of 1,000 replications; only the bootstrap values of more than $60 \%$ are shown, and the branch lengths are proportional to the genetic distances. The isolates obtained in this study are indicated by a triangle $(\triangle)$. Distance scale $=0.05$. The GenBank accession numbers for the ITS sequences of the reference isolates are listed in the bracket as follows: MAFF625034 (JQ807469), DP0590 (JQ807464), DP0438 (JQ807461) and DP0460 (JQ807463) of Phomopsis fukushii; DF5017 (JQ807449) and AR4373 (JQ807442) of Diaporthe eres; FAU1052 (AF102998) of $P$. amygdali; SSLP-1 (HQ333500) of P. logicolla; DP0188 (JQ807454) of D. netheicola; STE-U2660 (AF230751) of P. viticola; and 5.5.4r1(2) (KC143171) of D. ambigua. Botryosphaeria dothidea (ZH2211, KC960944) is added as an outgroup. revealed a clear divergence in the number of aerial hyphal rings, mycelial density and pigmentation, and distribution and quantity of pycnidia.

Phomopsis fukushii (69 isolates) formed snow-white colonies with dense mycelia and contained no less than two wide concentric rings of aerial hyphae in each colony. Spherical or oblate black pycnidia formed over the concentric rings and they were uncoated. The isolates were divided into two subgroups depending on the amount of aerial hyphal rings, with subgroup Ia (21 isolates) producing more than three hyphal rings with pycnidia uniformly distributed along the hyphal rings, whereas subgroup Ib (48 isolates) produced two aerial hyphal rings with the inner rings being wider than the outer ones. Thirteen isolates produced purple or light-gray pigments that were visible when plates were viewed upside-down (Fig. 3A).

$D$. eres (31 isolates) formed white colonies with thin mycelia and contained no less than two concentric aerial hyphal rings in each colony, with spherical or oblate black pycnidia uniformly distributed around the concentric rings. The isolates were divided into two subgroups depending on the manner of pycnidia formation. Isolates in subgroup IIa (23 isolates) formed uncoated pycnidia over the hyphal rings whereas subgroup $\mathrm{Ilb}$ ( 8 isolates) formed pycnidia coated by mycelia along the hyphal rings (Fig. 3A). Four isolates also produced purple or light-gray pigments on the undersides of the colonies (Fig. 3A).

P. amygdali (22 isolates) formed gray to black colonies with thin mycelia and contained inconspicuous aerial hyphal rings in each colony, with spherical or oblate black pycnidia scattered over the colony. Notable black pigments formed on the undersides of the colonies after 10 days of incubation but the mycelia on the upper colony surface remained white.

$P$. longicolla (13 isolates) formed white or oyster-colored colonies with thin, dense, and floccose mycelia. They produced no pigment on the undersides of the colonies, and their pycnidia were spherical or oblate, black, clearly smaller than those of other species, and were randomly scattered over the colonies (Fig. 3A).

D. neotheicola (8 isolates) formed a snow-white colony with sparse mycelia with abnormal or irregular margins, produced no pigment on the undersides of the colonies, and their pycnidia were spherical or oblate, black, coated with mycelia, and scattered over the colonies.

In all, 2 to 5 isolates (16 in total; Table 2 ) were chosen from each species according to their colony appearance as representatives for the characterization of their conidium morphology. After being cultured on PDA medium for 20 to 30 days, all the isolates could produce $\alpha$-conidia but only one to three isolates of each species also produced $\beta$-conidia (Table 2 ).

The $\alpha$-conidia of all the isolates were one-celled, hyaline, fusiform, aseptate, and frequently biguttulate (Fig. 3B), with lengths ranging from 4.97 to $11.01 \mu \mathrm{m}$ and widths from 1.51 to $4.28 \mu \mathrm{m}$. The sizes were significantly different among different isolates ( $F=11.139$ and $P<0.001$ for the lengths and $F=53.128$ and $P<$ 0.001 for the widths) (Table 2). The $\beta$-conidia of all the isolates were one-celled, aseptate, hyaline, and filiform with straight or curved ends (Fig. 3B), with lengths ranging from 17.30 to $48.98 \mu \mathrm{m}$ and widths from 0.99 to $2.69 \mu \mathrm{m}$. The sizes were significantly different among different isolates $(F=133.179$ and

Table 1. Host, sampling region and numbers of Phomopsis (Diaporthe) isolates obtained in the study

\begin{tabular}{|c|c|c|c|c|c|c|c|}
\hline \multirow[b]{2}{*}{ Sampling province } & \multirow[b]{2}{*}{ Host } & \multirow[b]{2}{*}{$N^{\mathbf{z}}$} & \multicolumn{5}{|c|}{ Proportion of isolates from each species } \\
\hline & & & Phomopsis fukushii & Diaporthe eres & P. amygdali & P. longicolla & D. neotheicola \\
\hline Jiangxi & Pyrus pyrifolia & 42 & 40.6 & 15.6 & 31.3 & 6.3 & 6.3 \\
\hline Hubei & P. pyrifolia & 14 & 35.7 & 35.7 & 0.0 & 28.6 & 0.0 \\
\hline Fujian & P. pyrifolia & 45 & 35.6 & 20.0 & 26.7 & 15.6 & 2.2 \\
\hline Shandong & P. communis & 15 & 73.3 & 26.7 & 0.0 & 0.0 & 0.0 \\
\hline Jiangsu & P. pyrifolia & 1 & 100.0 & 0.0 & 0.0 & 0.0 & 0.0 \\
\hline Yunnan & P. bretschneideri & 11 & 0.0 & 54.5 & 0.0 & 0.0 & 45.5 \\
\hline Shandong & Malus pumila & 15 & 86.7 & 13.3 & 0.0 & 0.0 & 0.0 \\
\hline Total & $\ldots$ & 143 & 371.9 & 165.9 & 57.9 & 50.4 & 53.9 \\
\hline
\end{tabular}

${ }^{\mathrm{z}}$ Number of Phomopsis (Diaporthe) isolates derived from the province. 
$P<0.001$ for the lengths and $F=17.998$ and $P<0.001$ for the widths) (Table 2).

Two representative isolates of each species were chosen to assess the growth rates (Fig. 4). The results showed that both isolates of each species had identical or similar growth rates, and the average growth rates were $12.5,10.8,13.3,15.0$, and 5.7 to $6.1 \mathrm{~mm}$ per day for the P. fukushii, D. eres, P. amygdali, P. longicolla, and D. neotheicola isolates, respectively. The growth rate was significantly different among some of the species $(F=89.440, P<0.001)$, of which $D$. neotheicola had the lowest growth rate, $D$. eres had a medium growth rate, and

A P. fukushii D. eres P. amygdail P. longicolla D. neotheicola

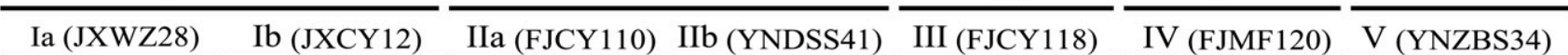
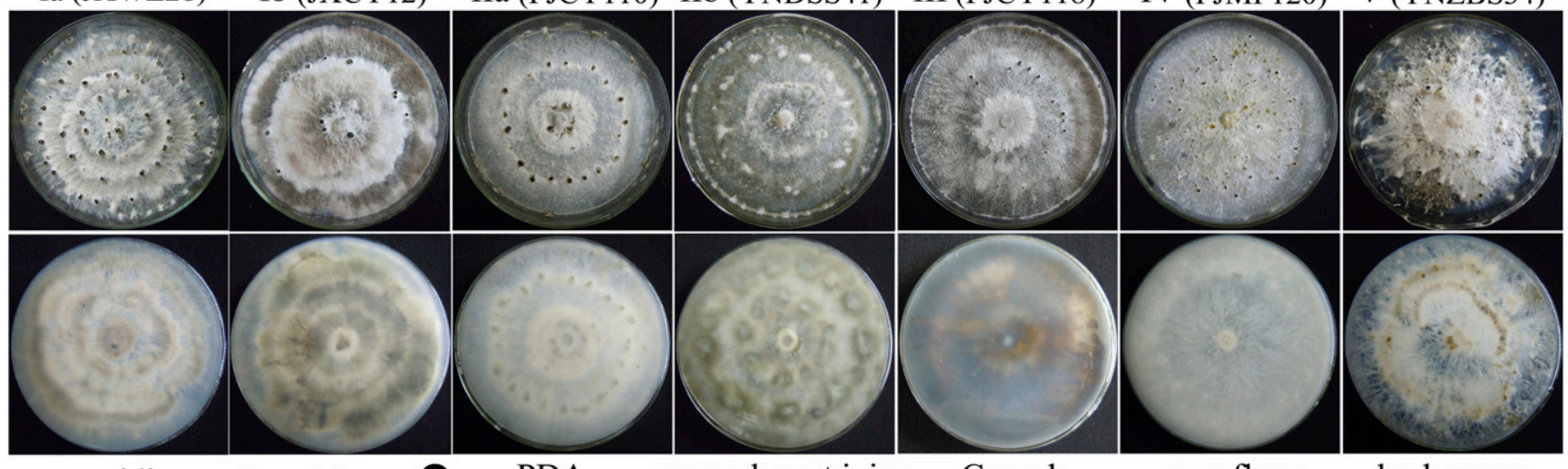

B
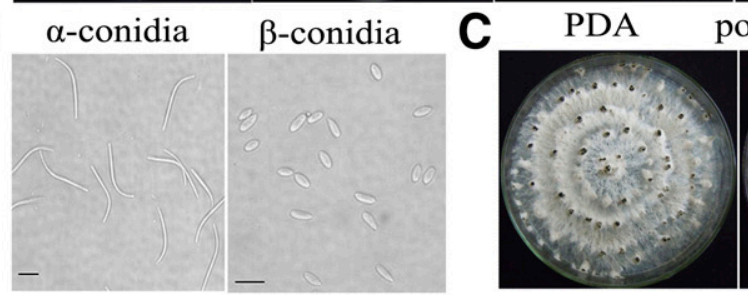

ome decoct juice

Czapek

corn flour

barleycorn

Fig. 3. Morphologies of the representative isolates belonging to five Phomopsis (Diaporthe) spp. obtained in this study. A, Colony appearance of representative isolates which were cultured on potato dextrose agar (PDA), with images taken after 18 days from above and $\mathbf{B}$, at the bottom, $\alpha$ - and $\beta$ - conidia, scale bar $=10 \mu \mathrm{m} ; \mathbf{C}$, above-colony appearance of JXWZ28 in Phomopsis fukushii cultured on PDA, pome decoct juice, Czapek, corn flour, and barleycorn medium at 13 days postinoculation.

Table 2. Morphological characteristics of the representative isolates of Phomopsis (Diaporthe) obtained in this study

\begin{tabular}{|c|c|c|c|c|c|c|c|c|}
\hline \multirow[b]{3}{*}{ Species, isolate } & \multicolumn{4}{|c|}{ Conidia size ranges ${ }^{x}$} & & & \multirow[b]{3}{*}{ Color $^{\mathrm{z}}$} & \multirow[b]{3}{*}{ Type } \\
\hline & \multicolumn{2}{|c|}{$\alpha$-Conidia } & \multicolumn{2}{|c|}{$\beta$-Conidia } & \multicolumn{2}{|c|}{ Means \pm SD of conidia size ${ }^{y}$} & & \\
\hline & Length & Width & Length & Width & $\alpha$-Conidia & $\beta$-Conidia & & \\
\hline \multicolumn{9}{|c|}{ Phomopsis fukushii } \\
\hline JXCY12 & $5.61-9.71 \mathrm{a}$ & $1.97-4.28 \mathrm{c}$ & $17.30-29.88 \mathrm{a}$ & $0.99-2.23 \mathrm{a}$ & $7.85 \pm 0.32 \times 2.89 \pm 0.50$ & $23.40 \pm 2.99 \times 1.46 \pm 0.32$ & $\mathrm{~W}$ & $\mathrm{~W}$ \\
\hline JXWZ25 & $5.93-8.99 \mathrm{a}$ & $1.98-2.23 \mathrm{a}$ & $\ldots$ & $\ldots$ & $7.73 \pm 0.45 \times 2.23 \pm 0.31$ & $\ldots$ & W & $\mathrm{W}$ \\
\hline JXWZ28 & $5.58-10.09 \mathrm{a}$ & $1.87-3.39 \mathrm{bc}$ & $23.37-43.85 \mathrm{~b}$ & $1.04-2.69 \mathrm{ab}$ & $7.88 \pm 0.5 \times 2.45 \pm 0.44$ & $29.05 \pm 2.98 \times 2.75 \pm 0.49$ & W-P & $\mathrm{G}$ \\
\hline SDFS71 & $5.35-9.85 \mathrm{ab}$ & $2.03-3.15 \mathrm{a}$ & $30.84-48.98 \mathrm{e}$ & $1.58-2.18 \mathrm{~cd}$ & $7.63 \pm 0.5 \times 2.35 \pm 0.41$ & $40.98 \pm 4.65 \times 1.87 \pm 0.16$ & $\mathrm{~W}$ & $\mathrm{~W}$ \\
\hline SDFS77 & $5.32-9.91 \mathrm{ab}$ & $2.08-3.39 \mathrm{c}$ & $\ldots$ & $\ldots$ & $7.61 \pm 0.90 \times 2.93 \pm 0.42$ & $\ldots$ & W-P & $\mathrm{G}$ \\
\hline \multicolumn{9}{|l|}{ Diaporthe eres } \\
\hline JXCXL13 & $5.07-10.08 \mathrm{a}$ & $1.87-3.05 \mathrm{~d}$ & $26.13-44.34 \mathrm{~cd}$ & $1.32-2.64 \mathrm{~d}$ & $7.70 \pm 1.10 \times 3.37 \pm 0.34$ & $33.20 \pm 3.93 \times 1.98 \pm 0.38$ & G & $\mathrm{G}$ \\
\hline HBJ2319 & $6.28-9.30 \mathrm{ab}$ & $1.87-3.97 \mathrm{c}$ & $\ldots$ & 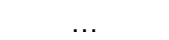 & $7.61 \pm 0.70 \times 2.96 \pm 0.47$ & 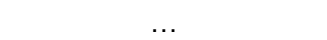 & $\mathrm{W}$ & $\mathrm{W}$ \\
\hline YNDSS41 & $5.88-10.51 \mathrm{a}$ & $1.51-3.28 \mathrm{a}$ & $24.79-36.98 \mathrm{c}$ & $1.34-2.33 \mathrm{bc}$ & $7.73 \pm 1.33 \times 2.31 \pm 0.42$ & $31.38 \pm 3.36 \times 1.79 \pm 0.24$ & G & $\mathrm{G}$ \\
\hline FJCY110 & $4.97-8.18 \mathrm{~d}$ & $1.51-3.14 \mathrm{a}$ & $20-35.61 \mathrm{~b}$ & $1.03-2.08 \mathrm{a}$ & $6.43 \pm 0.78 \times 2.26 \pm 0.36$ & $27.07 \pm 3.53 \times 1.59 \pm 0.27$ & W-G & $\mathrm{W}$ \\
\hline \multicolumn{9}{|l|}{ P. amygdail } \\
\hline JXCY 15 & $5.36-9.38 \mathrm{ab}$ & $2.03-3.21 \mathrm{bc}$ & $\ldots$ & $\ldots$ & $7.65 \pm 0.81 \times 2.65 \pm 0.39$ & $\ldots$ & G & G \\
\hline FJCY118 & $6.47-9.43 \mathrm{a}$ & $2.03-2.98 \mathrm{ab}$ & $\ldots$ & $\ldots$ & $7.85 \pm 0.82 \times 2.55 \pm 0.28$ & $\ldots$ & $\mathrm{G}$ & G \\
\hline JXYT181 & $5.33-10.36 \mathrm{a}$ & $1.83-3.31 \mathrm{~d}$ & $27.11-44.33 \mathrm{~d}$ & $1.35-2.68 \mathrm{~d}$ & $7.78 \pm 1.03 \times 3.39 \pm 0.38$ & $35.01 \pm 3.96 \times 1.99 \pm 0.39$ & G & G \\
\hline \multicolumn{9}{|l|}{ P. longicolla } \\
\hline FJMF120 & $5.25-11.01 \mathrm{bc}$ & $1.83-3.2 \mathrm{~b}$ & $29.03-40.31 \mathrm{~d}$ & $1.34-2.33 \mathrm{bc}$ & $7.64 \pm 1.01 \times 2.38 \pm 0.33$ & $34.72 \pm 2.64 \times 1.79 \pm 0.24$ & W & $\mathrm{W}$ \\
\hline HBCG59 & $5.25-8.99 \mathrm{ab}$ & $2.05-3.36 \mathrm{ab}$ & $\ldots$ & $\ldots$ & $7.07 \pm 0.76 \times 2.62 \pm 0.33$ & $\ldots$ & $\mathrm{W}$ & $\mathrm{W}$ \\
\hline \multicolumn{9}{|l|}{ D. neotheicola } \\
\hline FJHH134 & $5.61-8.10 \mathrm{ab}$ & $1.87-2.67 \mathrm{a}$ & $21.34-28.03 \mathrm{a}$ & $1.43-1.69 \mathrm{bc}$ & $6.74 \pm 0.62 \times 2.22 \pm 0.17$ & $25.01 \pm 2.63 \times 1.79 \pm 0.28$ & $\mathrm{~W}$ & $\mathrm{~W}$ \\
\hline YNZBS34 & $6.41-8.94 \mathrm{~cd}$ & $1.93-2.59 \mathrm{a}$ & $\ldots$ & $\ldots$ & $7.62 \pm 0.60 \times 2.21 \pm 0.17$ & $\ldots$ & $\mathrm{W}$ & $\mathrm{W}$ \\
\hline
\end{tabular}


$P$. longicolla had the highest growth rate, and the other two species (P. fukushii and $P$. amygdali) were positioned between $D$. eres and P. longicolla (Fig. 4).

Sporulation properties and germination tests. To prepare sufficient conidia to study the fungal pathogenicity and characterize the conidial sporulation properties, the five species were assessed by culturing one representative isolate (Supplementary Fig. S2) on five media: pome juice decoction, Czapek, corn flour, barleycorn, and PDA. The results showed a significant divergence in the time of pycnidial formation and conidial release among the five species and the five media tested. Most of the species formed pycnidia at earlier times ( 8 to 9 days) on the barleycorn medium, later times (20 to 30 days) on the pome juice medium, and somewhere in between on the other media (12 to 21 days) (Supplementary Fig. S2A). The pycnidia formation time was significantly different among the species on each medium, and P. fukushii, D. eres, and P. amygdail formed pycnidia earlier than $P$. longicolla and $D$. neotheicola on the PDA $(F=5.177$, $P=0.016)$, pome juice decoction $(F=11.613, P=0.001)$, and corn flour media $(F=13.406, P=0.001) ; D$. eres and $D$. neotheicola formed pycnidia later than the other species on Czapek medium $(F=109.5, P<0.001)$, and all the species had a similar formation time on the barleycorn medium $(F=2.250, P=0.136)$. The conidial release time was also significantly affected by the growing medium and the species. No conidia were released on the pome juice medium for any of the species, or on Czapek medium for D. eres, $P$. longicolla, and D. neotheicola. P. fukushii, D. eres, and P. amygdail released conidia earlier than P. longicolla and D. neotheicola on the barleycorn medium. The release time was similar on PDA and corn flour for these species, except that $D$. neotheicola had a later release time (Supplementary Fig. S2B). It is worth noting that large numbers of white spore tendrils were released from the pycnidia on barleycorn medium at 10 to $13 \mathrm{dpi}$ for all of the species (Fig. 3C).

The $P$. fukushii isolate was further evaluated to determine how the five different media affected colony appearance and spore production. The number of concentric hyphal rings varied depending on the medium, with three, two, zero, seven, and zero rings produced on PDA, pome juice decoction, Czapek, corn flour, and barleycorn, respectively. Purple pigment was produced in pome juice decoction medium and not in other media. The pycnidia were produced without being coated in mycelia in PDA, Czapek, and barleycorn medium but they were half-coated in mycelia in corn flour medium and pome juice decoction (Fig. 3C). The numbers of pycnidia also varied depending on the medium type. Approximately $50,3,100,90$, and 1,430 pycnidia were produced per plate for PDA, pome juice decoction, Czapek, corn flour, and barleycorn medium, respectively. Other species also exhibited similar effects of media on pycnidial production (data not shown). The barleycorn medium was chosen to prepare the conidium suspension for further pathogenicity analysis.

Sixteen isolates representative of the species (Table 2) were subjected to a germination test in PD culture solution. The $\alpha$-conidia easily germinated in PD culture solution, with a germination incidence of $100 \%$ after $4 \mathrm{~h}$ of incubation, but the $\beta$-conidia did not germinate under this condition, even after the culture time was prolonged for 10 days.

Pathogenicity analysis, host range analysis, and virulence assessment. Pathogenicity analysis on intact branches of Pyrus pyrifolia var. Cuiguan. Fourteen representative isolates (Fig. 5) were selected for pathogenicity analysis after observing that they could form $\alpha$-conidia in similar quantities over similar culture periods, whereas no $\beta$-conidia were ever observed in the spores released in this period. Pathogenicity analysis on intact branches of Pyrus pyrifolia var. Cuiguan showed that, under unwounded conditions, all the isolates belonging to Phomopsis fukushii, D. eres, and P. amygdali (except isolate FJHH135) started to induce small dark-brown canker lesions around the buds that were visible at $40 \mathrm{dpi}$. The small lesions quickly expanded into large brown or reddish lesions at high temperatures and under humid weather conditions (in May to June), and the lesions became depressed and cracked at the margins by $60 \mathrm{dpi}$ (Fig. 5A). The induced symptoms matched the ones observed in the field. The lesion lengths varied significantly among the different isolates $(F=7.945, P<0.001)$. None of the isolates of either $P$. longicolla or D. neotheicola induced any lesions, nor were lesions formed on the controls (Fig. 5A and B). After wounding, mycelium plug inoculations of attached branches from Cuiguan resulted in the quick emergence of the same reddish symptoms that were induced by all the isolates of $P$. fukushii, D. eres, $P$. amygdali, and $P$. longicolla at $15 \mathrm{dpi}$, whereas neither of the two isolates of D. neotheicola induced lesions (Supplementary Fig. S3A). No lesions developed on control branches inoculated with buffer. The lesion lengths varied significantly among the different isolates $(F=9.796, P<0.001)$. In late summer to early autumn, numerous small pycnidia formed along with the lenticels in the canker lesions. White spore tendrils were forced out of the lenticels after it rained later in the autumn, and they were similar to the ones observed in the field (Fig. 1E and F). All branches showing canker symptoms elicited by the inoculations were subjected to fungal isolation, and the results showed that the reisolated colonies matched the inoculated ones in their morphologies and ITS sequences (data not shown).

Pathogenicity analyses on the branches of other pear varieties. Twenty isolates (Supplementary Fig. S3B) from the five species were used for pathogenicity analyses conducted with mycelial inoculation of wounded, detached branches of Pyrus pyrifolia var. Hohsui under indoor conditions. The results showed that, except for one isolate

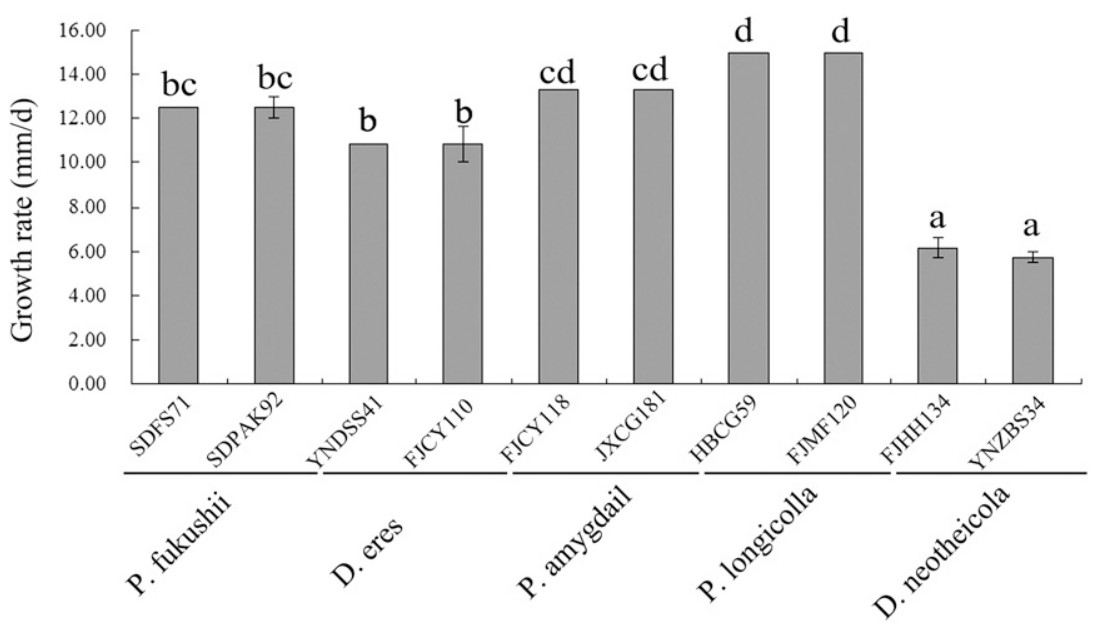

Fig. 4. Growth rates of two representative isolates of five Phomopsis (Diaporthe) spp. The isolates and the species involved are shown at the bottom of the colonies. Data were analyzed with SPSS Statistics 21.0 (WinWrap Basic; http://www.winwrap.com) by one-way analysis of variance, and means were compared using Tukey's test at a significance level of $P=0.05$. Letters over the bars indicate the significant difference at $P=0.05$. 
(YNZBS34) of D. neotheicola that produced no lesions, all the isolates started to induce black lesions at 2 dpi. The lesions turned reddish and significant differences were evident among different isolates and species by $15 \mathrm{dpi}(F=14.307, P<0.001)$. Most isolates from

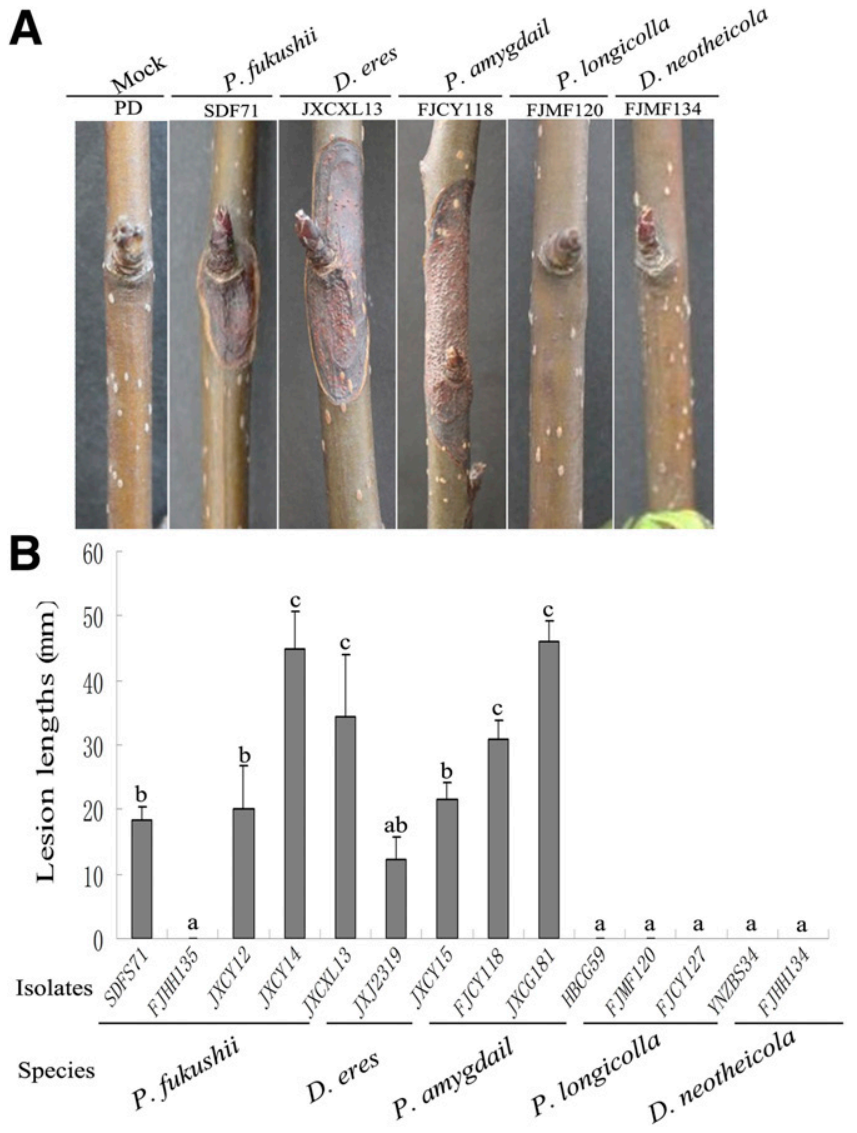

Fig. 5. Symptoms and lesion lengths induced by inoculation of unwounded attached pear branches (Pyrus pyrifolia var. Cuiguan) with spore suspensions $\left(10^{6} / \mathrm{ml}\right)$ from five Phomopsis (Diaporthe) spp. A, Representative symptoms as photographed at 60 days postinoculation (dpi). B, Mean lesions lengths from three replicates of branches measured at $60 \mathrm{dpi}$. Statistical analysis was performed with SPSS Statistics 21.0 (WinWrap Basic; http://www.winwrap.com) by one-way analysis of variance, and means were compared using Tukey's test at a significance level of $P=0.05$. Letters over the bars indicate the significant difference at the $P=0.05$ level.
Phomopsis fukushii, D. eres, and P. amygdali induced significantly longer lesions (12.0 to $48.2 \mathrm{~mm}$ ) than those produced by $D$. neotheicola (0 to $9.5 \mathrm{~mm}$ ) or $P$. longicolla $(10.2$ to $15.8 \mathrm{~mm}$ ). Similar virulence variation was obtained for the isolates (10 isolates of the 20 representative isolates) that were analyzed on Pyrus communis vars. Kndo and Poctor Jules Guyot on P. pyrifolia var. Hohsui (Supplementary Fig. S3C). No lesions were induced in the control branches inoculated with PDA plugs.

Host range analysis and virulence assessment. Two isolates from each Phomopsis spp. (Fig. 6) were chosen to analyze their host ranges in other rosaceous fruit species that are commonly grown in China, including apple (M. pumila Mill. var. Fushi), crabapple (M. spectabilis (Ait.) Borkh), hawthorn (Crataegus pinnatifida Bunge), cherry (Cerasus pseudocerasus (Lindl.) G. Don), and peach (Prunus persica (L) Batsch). Two nonrosaceous fruit species, kiwifruit (Actinidia chinensis Planch.) and citrus (Citrus reticulata Blanco), were also tested. The results showed that all the fungal species induced obvious lesions and decayed the xylem on the inoculated branches of apple, peach, crabapple, and cherry fruit, except that D. neotheicola isolate YNZB34 did not induce lesions in crabapple, and isolate FJHH134 induced no lesions on any of the inoculated branches (Fig. 6). None of the isolates induced lesions on hawthorn or citrus. Lesion lengths varied depending on both fungal species and plant species. In apple and crabapple branches $(F=$ 80.569 and 394.432, respectively, $P<0.001$ ), both Phomopsis amygdali isolates induced significantly longer lesions than the other species, with gradually shorter lesion lengths for $P$. fukushii, $D$. eres, $P$. longicolla, and $D$. neotheicola. In cherry, all the species induced longer lesions than in other plant branches $(F=64.948$ to 234.459, $P<0.001$ ), except the $D$. neotheicola isolate YNZB34, which still induced short lesions similar to the lesion lengths on other plants $(F=1.414, P=0.301)$. In peach and kiwifruit branches $(F=56.582$ and 87.265 , respectively, $P<0.001$ ), most of the isolated species induced similarly sized but significantly longer lesions than those induced by the D. neotheicola isolate (Fig. 6).

\section{Discussion}

This study presents the first attempt to characterize the Phomopsis spp. associated with pear branch canker disease (i.e., pear shoot canker) in China; it provides solid evidence that $P$. fukushii, D. eres, and $P$. amygdali were responsible for the pear shoot canker disease in single or mixed infections and that $P$. longicolla and $D$. neotheicola only posed a virulence risk to wounded plants.

In this study, 181 samples were collected from 11 varieties of three pear species from the six primary pear-producing provinces. To our knowledge, this is the first survey of its kind of this disease. Given

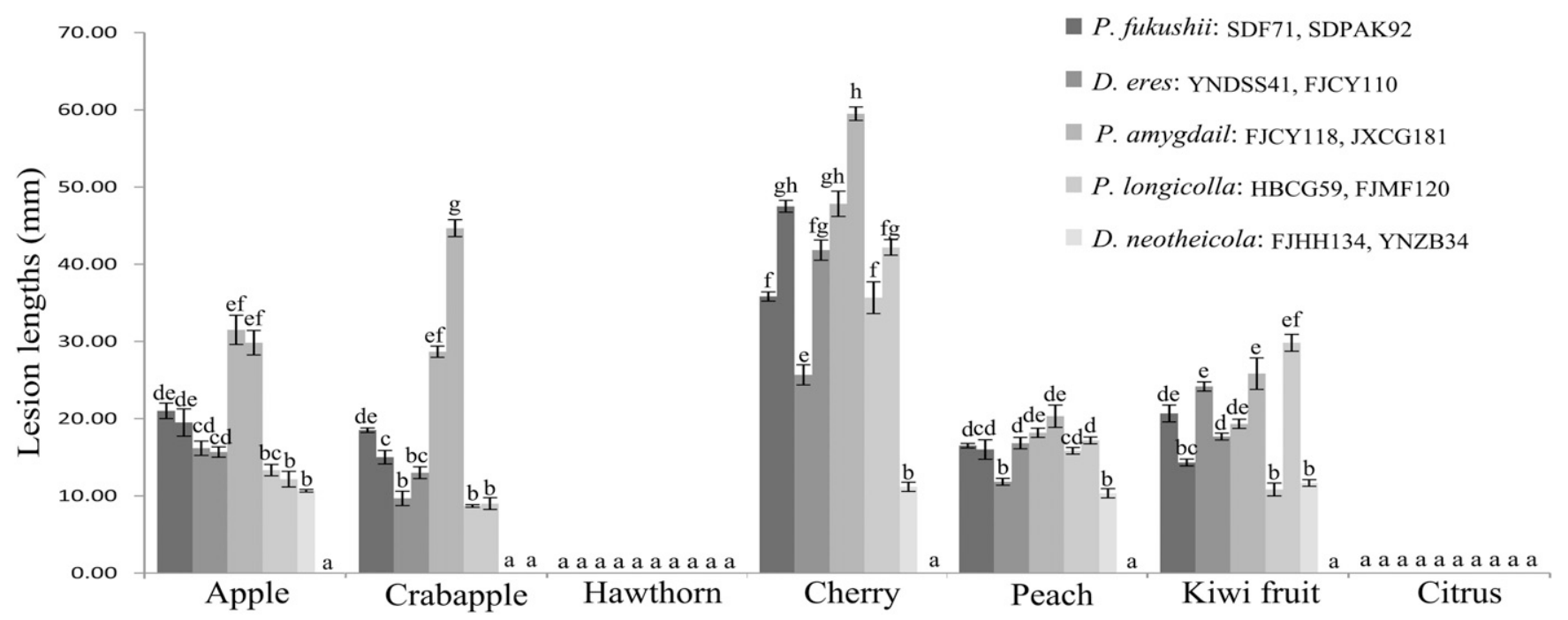

Fig. 6. Lesion lengths induced by inoculation of three replicates of detached nonwounded branches of seven fruit species using mycelial plugs from representative isolates of five Phomopsis (Diaporthe) spp., as measured at 10 days postinoculation. Statistical analysis was performed with SPSS Statistics 21.0 (WinWrap Basic; http://www.winwrap.com) by one-way analysis of variance, and means were compared using Tukey's test at a significance level of $P=0.05$. Letters over the bars indicate the significant difference at the $P=0.05$ level. 
that the pear and apple trees were grown in mixed plantings or at least in close proximity in many regions, some symptomatic apple samples close to pear orchards were also collected for fungal isolation, and 13 P. fukushii and 2 D. eres isolates were obtained from apple. The morphology, pathogenicity, and host range analysis of the representative isolates from apple exhibited no obvious difference from those from pear, and Koch's postulate was also followed with one isolate (SDFS71), showing that the isolate was also able to induce pear branch canker (Fig. 5A and B). These results suggest that the $P$. fukushii and D. eres isolates that infected apple trees had no clear biological divergence from those infecting pear trees, and diseased apple branches could also act as a source of infection that resulted in the pear branch canker observed in the field.

Molecular sequence analyses combined with morphology, host affiliation, and cultural and pathological data have been adopted to identify Phomopsis spp. (Aa et al. 1990; Mostert et al. 2001; Rehner and Uecker 1994; Santos and Phillips 2009; Santos et al. 2011; Shenoy et al. 2007; van Niekerk et al. 2005; van Rensburg et al. 2006). In fact, the current confirmation of the taxonomic status of the species in this genus relies heavily on molecular techniques (Castlebury 2005; Castlebury et al. 2003; Crous and Groenewald 2005; Santos et al. 2010; Udayanga et al. 2012). In this study, the species was identified by performing a phylogenetic analysis of ITS, which was confirmed by further phylogenetic analysis based on multilocus regions (ITS, actin, and EF1- $\alpha$ ). Among these regions, rDNA ITS and partial sequences of the EF1- $\alpha$ have commonly been used for molecular identification (Santos et al. 2010, 2011; Sun et al. 2012; Udayanga et al. 2012; van Niekerk et al. 2005; van Rensburg et al. 2006), and the multiloci sequence analysis has been used in species identifications of Phomopsis isolates from grapevines (Baumgartner et al. 2013).

Analysis of our isolates revealed that $P$. fukushii was the most common species, that $D$. eres and $P$. amygdali were also associated with the disease, and that $P$. longicolla and $D$. neotheicola were far less common. An analysis of the species with their host and sampling regions showed a correlation between the species and the host or region (Table 1), suggesting that the specific species might be related to the disease that occurred on different host varieties in different regions. Among these species, D. eres could be responsible for the branch canker of Pyrus bretschneideri in Yunnan, both Phomopsis fukushii and D. eres in Pyrus communis and M. pumila from Shandong and $P$. pyrifolia in most provinces, as well as Phomopsis amygdali in Pyrus pyrifolia from Jiangxi and Fujian together with Phomopsis fukushii and D. eres.

Colony morphologies differed among the species in the current study, with obvious divergence in number and appearance of mycelial rings, pigment production, and the distribution, size, and quantity of pycnidia (Fig. 3C), although some P. fukushii and D. eres isolates exhibited similar colony morphologies. These two species were also poorly resolved in previous studies of host specificity (Kanematsu et al. 2000; Udayanga et al. 2011). Most of the features remained stable in subcultures and colony pigments were used only to allocate groups into white or gray types (W or G type) within a species in a previous study (Kanematsu et al. 2000). According to the pigments of the isolates obtained in this study, all the isolates of $P$. longicolla and $D$. neotheicola were W types, whereas all the $P$. amygdali isolates were G types, except that $P$. fukushii and $D$. eres contained both types of isolates (13 and 4 isolates, respectively; Table 2). $P$. amygdali had been shown to be cross-fertile with the G-type isolates in another study (Kanematsu et al. 2000). Consistent with both of the previous reports, we also found that the G-type isolates had distinctly higher virulence than the W-type for most isolates of the five species, especially for isolates of P. amygdali, P. longicolla, and D. neotheicola (Fig. 5; Table 2).

All the species we studied produced two types of conidia ( $\alpha$ - and $\beta$-conidia), with similar shapes for each type (Table 2 ). Our results differ from a previous study, wherein the G-type isolates produced no $\beta$-conidia (Kanematsu et al. 2000), but are consistent with a recent report that $P$. amygdali isolates from Pieris japonica readily produced $\beta$-conidia (Bienapfl and Balci 2013). Compared with the $\alpha$-conidia sizes from the Phomopsis fukushii that was isolated from Japanese pear and apple in Japan (6.1 to 6.9 by 2.1 to $2.7 \mu \mathrm{m}$ ), the isolates obtained in this study had larger $\alpha$-conidia ( 7.61 to 7.88 by 2.23 to 3.37 ) (Kanematsu et al. 2000). The $\alpha$ - and $\beta$-conidia differed in size among different isolates but the difference was not related to the species types (Table 2). Therefore, as in previous reports, the micromorphology was not very useful for species definition (Baumgartner et al. 2013; Kanematsu et al. 2000). However, an evaluation of the growth rate revealed a significant difference among and within species, with isolates of $D$. neotheicola having the lowest growth rate (5.7 to $6.1 \mathrm{~mm}$ per day), which was similar to the slow-growing species on PDA $(5.2 \pm 0.2 \mathrm{~mm} /$ day) in a recent report (Udayanga et al. 2014).

Pathogenicity tests using conidial suspensions to inoculate intact branches of Pyrus pyrifolia var. Cuiguan and the subsequent reisolation of the same species from the diseased branches verified that three species (Phomopsis fukushii, D. eres, and P. amygdali) are responsible for pear branch canker disease. This conclusion was also supported by the observation that the three species were isolated at markedly higher frequencies (122 isolates) than either of the other two Phomopsis spp. (21 isolates) or than the other fungal genera (36 isolates) that were found in a broader range of pear species and regions (Table 1). The Phomopsis spp. induced canker symptoms after a conidia suspension was inoculated on the buds, which is consistent with the conclusion that the disease was invoked by fungal invasion via the buds (Melanson et al. 2002; Udayanga et al. 2011). Only $\alpha$-conidia germinated whereas $\beta$-conidia did not, as reported (Uecker 1988), suggesting that infections are initiated by $\alpha$-conidia alone rather than by $\beta$-conidia. When the plants were wounded, $P$. longicolla also induced canker lesions in the intact branches just as the first three species did, suggesting that the species could be an opportunistic pathogen associated with the disease. However, both $D$. neotheicola isolates induced no lesions when a wound was present, suggesting that the species might be nonpathogenic to this pear variety. A pathogenicity tests on pear fruit from Pyrus bretschneideri var. Huangguan showed that all five species can damage wounded pear fruit (data not shown). Phomopsis fukushii had previously been reported as the cause of a fruit rot of Chinese white pear (Pyrus ussuriensis Maximowicz var. sinensis Kikuchi) and Japanese pear (P. serotina Rehder var. cuta Rehder) (Nasu et al. 1987). Phomopsis spp. had been identified as the pathogen responsible for pear shoot canker in Japan, and it inhibits trunk growth and causes dead twigs and chronic canker or fruit rot of deciduous fruit trees (Tanaka and Endo 1930). We concluded that the pear branch canker disease in China is identical to the one described in Japan.

The host range evaluation suggested that all five Phomopsis spp. can attack most fruit trees belonging to the Rosaceae family as well as some nonrosaceous plants; however, virulence varied depending on the species of both the pathogen and the host. This result suggests that the fungus species derived from pear or apple has the potential to cause disease in other stone and pome fruit trees, and vice versa, as it did by cross-infection with three Phomopsis isolates from peach, plum, and Asian pear (Uddin and Stevenson 1998). It notable that the Phomopsis amygdali isolates had dramatically higher virulence than other species in all the tested Rosaceae plants. All fungal species were highly pathogenic in cherry but had similar and lower virulence risks in peach and kiwifruit. D. neotheicola posed little or no virulence risk in all the tested plant branches (Fig. 6).

$P$. fukushii was identified first as the pathogen responsible for the pear shoot canker in Japan (Tanaka and Endo 1930) and then on more Pyrus and Malus spp. (Farr and Rossman 2015; Nasu et al. 1987; Tanaka and Endo 1930) and grapevine from North America showing wood canker (Baumgartner et al. 2013). D. eres was shown to infect a broad range of plants encompassing approximately 300 species and causes cankers, fruit rots, and leaf spot diseases (Udayanga et al. 2011), whereas pear trees have reportedly not been damaged by this species (Farr and Rossman 2015). P. amygdali was only reported as responsible for the shoot canker of peach and almond (Bienapfl and Balci 2013; Tuset and Portilla 1989). P. longicolla was originally described from soybean in association with soybean seed decay and isolated from Abutilon theophrasti, Arachis hypogaea, Chamaesyce nutans, Ipomoea lacunosa, and Xanthium strumarium (Li et al. 2010a,b; Udayanga et al. 2011). D. neotheicola was associated with 
fruit trees, including Prunus and Pyrus spp., and Vitis vinifera, and there was no information about its pathogenicity. To our knowledge, this is the first clarification that $D$. eres and $P$. amygdali are responsible for the pear shoot canker disease, and our results also expand the host and geographic ranges of the five species. This study provides useful information to understand this pathogen and improve management strategies for controlling this economically important disease.

\section{Acknowledgments}

This study was financially supported by the earmarked fund for Pear Modern Agro-industry Technology Research System (CARS-29-10) and the Chinese Ministry of Agriculture, Industry Technology Research Project (grant number 201203034-02). We thank C. Luo, Huazhong Agricultural University, China, for critical revisions of the manuscript.

\section{Literature Cited}

Aa, H. A., van der Noordeloos, M. E., and Gruyter, J. 1990. Species concepts in some larger genera of the coelomycetes. Stud. Mycol. 32:3-19.

Baumgartner, K., Fujiyoshi, P. T., Travadon, R., Castlebury, L. A., Wilcox, W. F., and Rolshausen, P. E. 2013. Characterization of species of Diaporthe from wood cankers of grape in eastern North American vineyards. Plant Dis. 97:912-920.

Bienapfl, J. C., and Balci, Y. 2013. Phomopsis blight: A new disease of Pieris japonica caused by Phomopsis amygdali in the United States. Plant Dis. 97:1403-1407.

Carbone, I., and Kohn, L. M. 1999. A method for designing primer sets for speciation studies in filamentous ascomycetes. Mycologia 91:553-556.

Castlebury, L. 2005. The Diaporthe vaccinii complex of fruit pathogens. Inoculum $56: 12$

Castlebury, L. A., Farr, D. F., Rossman, A. Y., and Jaklitsch, W. J. 2003. Diaporthe angelicae comb. nov., a modern description and placement of Diaporthopsis in Diaporthe. Mycoscience 44:203-208.

Crous, P. W., and Groenewald, J. Z. 2005. Hosts, species and genotypes: Opinions versus data. Australas. Plant Pathol. 34:463-470.

Fang, Z. D. 1998. Methodology for Plant Pathology, 3rd ed. China Agriculture Press, Beijing.

Farr, D. F., and Rossman, A. Y. 2015. Fungal databases, systematic mycology and microbiology laboratory. Online publication. United States Department of Agriculture-Agricultural Research Service. http://nt.ars-grin.gov/fungaldatabases/

Freeman, S., Katan, T., and Shabi, E. 1996. Characterization of Colletotrichum gloeosporioides isolates from avocado and almond fruits with molecular and pathogenicity tests. Appl. Environ. Microbiol. 62:1014-1020.

Huang, D., Zhou, C., Xu, L., and Xie, J. 2014. Comprehensive prevention and control measures of a new disease showing shoot canker on early-maturing pear plant in Jiangxi, China. Mod. Hortic. 1:67-68.

Kanematsu, S., Minaka, N., Kobayashi, T., Kudo, A., and Ohtsu, Y. 2000. Molecular phylogenetic analysis of ribosomal DNA internal transcribed spacer regions and comparison of fertility in Phomopsis isolates from fruit trees. J. Gen. Plant Pathol. 66:191-201.

Li, S., Hartman, G. L., and Boykin, D. L. 2010a. Aggressiveness of Phomopsis longicolla and other Phomopsis spp. on soybean. Plant Dis. 94:1035-1040.

Li, Y. Y., Wang, M. Z., Huang, Y. J., and Shen, Y. M. 2010b. Secondary metabolites from Phomopsis sp. A123. Mycology 1:254-261.

Melanson, D. L., Rawnsley, B., and Scheper, R. W. A. 2002. Molecular detection of Phomopsis taxa 1 and 2 in grapevine canes and buds. Australas. Plant Pathol. 31: $67-73$

Mostert, L., Crous, P. W., Kang, J. C., and Phillips, A. J. L. 2001. Species of Phomopsis and a Libertella sp. occurring on grapevines with specific reference to South Africa: Morphological, cultural, molecular and pathological characterization. Mycologia 93:146-167.

Nasu, H., Hatamoto, M., Date, H., and Fuji, S. 1987. Pear fruit rot caused by agents of Japanese pear canker, Phomopsis fukushii and blossom end rot of European pear, Phomopsis sp. Jpn. J. Phytopathol. 53:630-637.

Rehner, S. A., and Uecker, F. A. 1994. Nuclear ribosomal internal transcribed spacer phylogeny and host diversity in the coelomycete Phomopsis. Can. J. Cardiol. 72:1666-1674.

Rubtsov, G. A. 1944. Geographical distribution of the genus Pyrus and trends and factors in its evolution. Am. Nat. 78:358-366.
Santos, J. M., Correia, V. G., and Phillips, A. J. L. 2010. Primers for mating-type diagnosis in Diaporthe and Phomopsis: Their use in teleomorph induction in vitro and biological species definition. Fungal Biol. 114:255-270.

Santos, J. M., and Phillips, A. J. L. 2009. Resolving the complex of Diaporthe (Phomopsis) species occurring on Foeniculum vulgare in Portugal. Fungal Divers. 34:111-125.

Santos, J. M., Vrandečić, K., Ćosić, J., Duvnjak, T., and Phillips, A. J. L. 2011. Resolving the Diaporthe species occurring on soybean in Croatia. Persoonia 27:9-19.

Sawamura, K., Harada, Y., and Yakita, K. 1990. Apple Valsa canker caused by Valsa ceratosperma (Tobe ex. Fr.) Maire. Hirosaki Bull. Fac. Agric. 53 $10-32$

Shenoy, B. D., Jeewon, R., and Hyde, K. D. 2007. Impact of DNA sequence data on the taxonomy of anamorphic fungi. Fungal Divers. 56:157-171.

Smit, W. A., Viljoen, C. D., Wingfield, B. D., Wingfield, M. J., and Calitz, F. J. 1996. A new canker disease of apple, pear, and plum rootstocks caused by Diaporthe ambigua in South Africa. Plant Dis. 80:1331-1335.

Sun, S., Van, K., Kim, M. Y., Min, K. H., Lee, Y. W., and Lee, S. H. 2012. Diaporthe phaseolorum var. caulivora, a causal agent for both stem canker and seed decay on soybean. Plant Pathol. J. 28:55-59.

Tamura, K., Peterson, D., Peterson, N., Stecher, G., Nei, M., and Kumar, S. 2011 MEGA5: Molecular evolutionary genetics analysis using maximum likelihood, evolutionary distance, and maximum parsimony methods. Mol. Biol. Evol. 28: 2731-2739.

Tanaka, S., and Endo, S. 1930. Studies on a new canker disease of Japanese pear trees caused by Phomopsis fukushii n. sp. Trans. Tottori Soc. Agric. Sci. 2 123-134.

Tuset, J. J., and Portilla, M. T. 1989. Taxonomic status of Fusicoccum amygdali and Phomopsis amygdalina. Can. J. Bot. 67:1275-1280.

Udayanga, D., Castlebury, L. A., Rossman, A. Y., and Hyde, K. D. 2014. Species limits in Diaporthe: Molecular re-assessment of D. citri, D. cytosporella, D. foeniculina and D. rudis. Persoonia 32:83-101.

Udayanga, D., Liu, X., Crous, P. W., McKenzie, E. H., Chukeatirote, E., and Hyde, K. D. 2012. A multi-locus phylogenetic evaluation of Diaporthe (Phomopsis) Fungal Divers. 56:157-171.

Udayanga, D., Liu, X., McKenzie, E. H. C., Chukeatirote, E., Bahkali, A. H. A., and Hyde, K. D. 2011. The genus Phomopsis: Biology, applications, species concepts and names of common phytopathogens. Fungal Divers. 50:189-225.

Uddin, W., and Stevenson, K. L. 1998. Pathogenic and molecular characterization of three Phomopsis isolates from peach, plum and Asian pear. Plant Dis. 82 732-737.

Uecker, F. A. 1988. World List of Phomopsis Names with Notes on Nomenclature, Morphology, and Biology. Mycologia Memoir, no. 13. J. Cramer, Berlin.

van Niekerk, J. M., Groenewald, J. Z., Farr, D. F., Fourie, P. H., Halleer, F., and Crous, P. W. 2005. Reassessment of Phomopsis species on grapevines. Australas. Plant Pathol. 34:27-39.

van Rensburg, J. J. C., Lamprecht, S. C., Groenewald, J. Z., Castlebury, L. A., and Crous, P. W. 2006. Characterisation of Phomopsis spp. associated with dieback of rooibos (Aspalathus linearis) in South Africa. Stud. Mycol. 55:65-74.

Vavilov, N. I. 1951. The origin, variation, immunity and breeding of cultivated plants. Soil Sci. 72:482.

Wu, J., Wang, Z., Shi, Z., Zhang, S., Ming, R., Zhu, S., Khan, M., Tao, S., Korban, S., Wang, H., Chen, N., Nishio, T., Xu, X., Cong, L., Qi, K., Huang, X., Wang, Y., Zhao, X., Wu, J., Deng, C., Gou, C., Zhou, W., Yin, H., Qin, G., Sha, Y. Tao, Y., Chen, H., Yang, Y., Song, Y., Zhan, D., Wang, J., Li, L., Dai, M., Gu, C., Wang, Y., Shi, D., Wang, X., Zhang, H., Zeng, L., Zheng, D., Wang, C., Chen, M., Wang, G., Xie, L., Sovero, V., Sha, S., Huang, W., Zhang, S. Zhang, M., Sun, J., Xu, L., Li, Y., Liu, X., Li, Q., Shen, J., Wang, J., Paull, R., Bennetzen, J., Wang, J., and Zhang, S. 2013. The genome of the pear (Pyrus bretschneideri Rehd.). Genome Res. 23:396-408

Zeven, A. C., and Zhukovsky, P. M. 1975. Dictionary of Cultivated Plants and Their Centers of Diversity. Center for Agricultural Publishing and Documentation, Wageningen, The Netherlands.

Zhai, L., Zhang, M., Lv, G., Chen, X., Jia, N., Hong, N., and Wang, G. 2014 Biological and molecular characterization of four Botryosphaeria species isolated from pear plants showing stem wart and stem canker in China. Plant Dis. 98:716-726.

Zhao, H., Wang, C. X., Chen, X. R., Wang, H. Y., and Li, B. H. 2012. Methods of promoting sporulation of Valsa ceratosperma. Chin. Agric. Sci. Bull. 10:152-154. 